This item was submitted to Loughborough's Research Repository by the author.

Items in Figshare are protected by copyright, with all rights reserved, unless otherwise indicated.

\title{
A preliminary investigation into the apparent abhesive effect of stearic acid on cured silicone elastomer
}

PLEASE CITE THE PUBLISHED VERSION

http://dx.doi.org/10.1016/j.ijadhadh.2010.09.001

PUBLISHER

Elsevier (@ Crown Copyright)

VERSION

AM (Accepted Manuscript)

LICENCE

CC BY-NC-ND 4.0

\section{REPOSITORY RECORD}

Ana, U.J., Gary W. Critchlow, K.M. Ford, N.R. Godfrey, David B. Grandy, and M.A. Spence. 2010. "A Preliminary Investigation into the Apparent Abhesive Effect of Stearic Acid on Cured Silicone Elastomer". figshare. https://hdl.handle.net/2134/6676. 
This item was submitted to Loughborough's Institutional Repository (https://dspace.lboro.ac.uk/) by the author and is made available under the following Creative Commons Licence conditions.

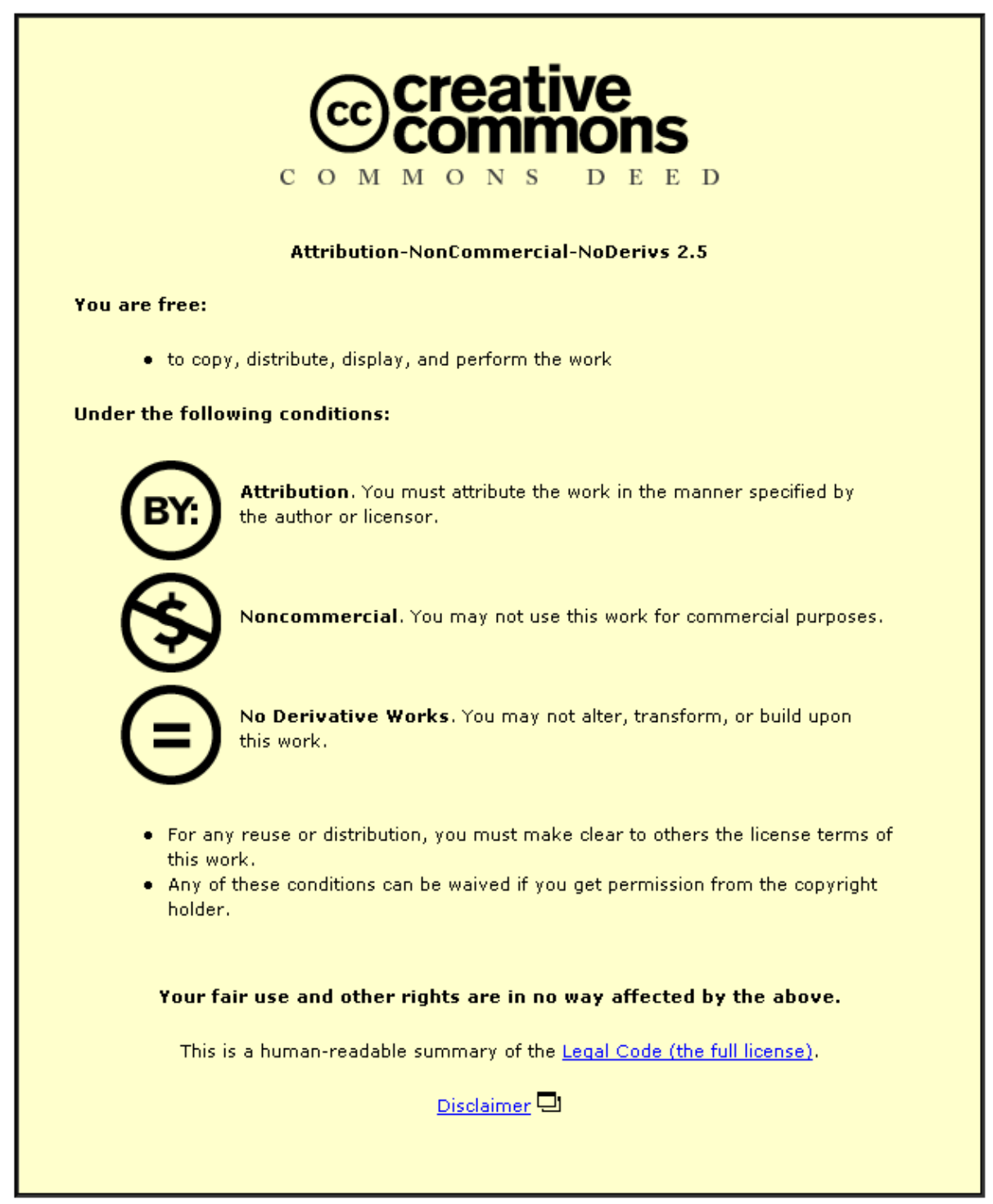

For the full text of this licence, please go to: http://creativecommons.org/licenses/by-nc-nd/2.5/ 


\title{
A Preliminary Investigation into the Apparent Abhesive Effect of Stearic Acid
} on Cured Silicone Elastomer

U. J. Ana ${ }^{1}$, G.W Critchlow ${ }^{1}$ K.M. Ford ${ }^{2}$, N.R. Godfrey ${ }^{2}$, D.B. Grandy ${ }^{1}$ and M.A. Spence $^{2}$

${ }^{1}$ Department of Materials, Loughborough University, Loughborough LE11 3TU

${ }^{2}$ AWE plc, Aldermaston, Reading, RG7 4PR

*Corresponding author: Tel.: +44 (0)118 982 7659, Fax: +44 (0)118 982 4739, E-mail address: kathryn.ford@awe.co.uk

(C) British Crown Owned Copyright 2010/MOD

\begin{abstract}
The effect of addition of small amounts of stearic acid on the adhesive properties of polydimethylsiloxane (PDMS) was investigated. Stearic acid reduced the peel strength of bonded aluminium samples with the joint weakening effect increasing with increased loadings. Surface analysis of the peeled surfaces was carried out using XPS, SSIMS and FTIR. This showed that stearic acid did not form a weak boundary layer at the metal-polymer interface as would traditionally be expected. Local Force Microscopy confirmed this, as the surface adhesion of the PDMS increased, rather than decreased, on addition of stearic acid.
\end{abstract}

Keywords: Silicones (A), Atomic Force Microscopy (C), Peel (C), Abhesion/nonstick (D) 


\section{Introduction}

For both economic and environmental reasons there is an increasing demand on industry to re-use and recycle components when products are taken out of service. For new vehicles this requirement is defined by legislation such as the European and Japanese 'End of Life Vehicle' directives [1-3]. Many multi-component systems are adhesively bonded to join components of dissimilar materials and shapes. When such systems are disassembled it is necessary to break the adhesive bonds in a controlled manor so that components can be separated for re-use or recycling without damage or excessively long working times.

Long chain carboxylic acids are commonly used as additives in rubber processing and have proved to aid mould release [4-6]. A large number of patents for rubber and plastic products include use of stearic acid or a metal stearate as a processing aid. Some examples include sodium stearate in polyethylene terephthalate (PET) compounds [7], zinc carboxylates containing 8-24 carbon atoms per carboxylate group in polyurethane elastomer mouldings [8], zinc stearate in reinforced thermoplastics [9] and stearic or palmitic acid as a lubricant in acrylonitrile butadiene styrene (ABS) and styrene acrylonitrile (SAN) polymers [10].

There is evidence that longer chain molecules such as stearic acid are more effective mould release agents than shorter chain molecules such as lauric acid [11]. As well as use as a mould release agent in component manufacture, this sort of additive with abhesive properties may be used to control the strength of adhesive bonds to aid separation of bonded components. It is commonly believed that stearic acid aids mould release and reduces the observed levels of adhesion by forming a weak 
boundary layer (WBL) at the polymer or adhesive surface which will fail cohesively [4].

This paper describes investigations carried out to provide an explanation for the observed adhesion-reducing effect of addition of small amounts of stearic acid to the commercially available polydimethylsiloxane (PDMS) Sylgard $184^{\mathrm{TM}}$. Sylgard $184^{\mathrm{TM}}$ is a two part platinum catalysed addition curing material produced by Dow Corning. Addition curing occurs via pendant vinyl groups on the silicone polymer backbone [12]. The reaction is accelerated either thermally or using a chemical cure accelerator. Sylgard $184^{\mathrm{TM}}$ is supplied as a two pack product with the backbone monomer in 'Part A' and the cross-linker in 'Part B'. The platinum based catalyst is in both parts. An inhibitor is also contained in the mixture to slow the reaction to aid use of the material. For the mixture of 'Part A' and 'Part B' to cure either the mixture is heated, or a cure accelerator is used to overcome the activation barrier to reaction caused by the inhibitor. Figure 1 shows the cure reaction of a typical PDMS system [12]. In this study peel tests were used with bonded aluminium foil substrates to measure large scale adhesive properties and Local Force Microscopy was performed on the cured PDMS surface to measure adhesion over smaller scales.

Peel tests are commonly used for testing sealants and pressure sensitive adhesives. PDMS falls into this category as it is a rubbery material and in its cured state, the material surface remains slightly tacky, giving it pressure sensitive properties.

A number of standard peel test configurations are available including T-peel tests for flexible-to-flexible substrate bonding [13] along with $90^{\circ}[14,15]$ and $180^{\circ}$ peel tests [16] for flexible to rigid assemblies. Joint configurations for these tests are shown in Figure 2. Other, more complex peel test configurations include the climbing drum 
[17], floating roller [18] and mandrel peel tests. The BS and ASTM standard tests cited outline the bonding configuration, testing conditions and values to be reported for the peel tests.

The T-peel test is often the most suitable test for flexible-to-flexible assemblies and is the configuration selected for this study of the effect of stearic acid on adhesive joint strength. The authors have also investigated the effect of stearic acid on samples bonded with cured silicone rubber in $90^{\circ}$ and $180^{\circ}$ peel tests [19]. This data is not presented here as different surface preparation techniques were used for the different test configurations, making the results not truly comparable with the T-peel test results presented.

In the T-peel the unbonded end of both substrates is pulled apart at an angle of $180^{\circ}$ and fixed in the grips of the testing machine. The peel angle is not strictly $180^{\circ}$ throughout the test but varies according to the bending stiffness of the peeled substrates [20]. The joint is pulled apart at a constant crosshead separation rate and the force required to do this is measured. As with mechanical tests using rigid adhesives, a crack grows from the initiation point into the bonded area. The peel test can bring about crack growth in the adhesive (asymmetric cohesive failure) or it may bring about interfacial failure at the bond between the adhesive and substrate [21]. At the crack tip the peeling causes a compressive zone and induces shear stresses in addition to the tensile stresses experienced by the adhesive and interface [22].

The work of adhesion, i.e. the energy required to break an adhesive bond and make two new surfaces, can be defined as:

$$
\Delta \gamma=\gamma_{1}+\gamma_{2}-\gamma_{12}
$$

\section{Equation 1}


Where $\Delta \gamma$ is the work of adhesion, $\gamma_{1}$ and $\gamma_{2}$ are the surface energies of the two new surfaces created and $\gamma_{12}$ is the interfacial energy between the two materials in contact $[22,23]$.

However, in a peel test the overall peel energy is influenced not only by the work of adhesion but also by plastic, viscoelastic, bending properties of the bonded system and other factors relating to the materials and experimental conditions.

As such, the peel energy is more accurately defined as:

$P=\Delta \gamma+\psi_{\text {plast }}+\psi_{v e}+\psi_{\text {bend }}+\ldots$ Equation 2[20]

Peel energy and work of adhesion are thermodynamic parameters, which are independent of separation rate, thickness of adhesive or other parameters affecting the physical properties of the bulk adhesive. They can be calculated from the results of mechanical testing but more often, the force required to break an adhesive joint is measured and reported.

Provided that factors such as the backing materials, surface treatments etc. are controlled, mechanical tests of different adhesive systems may be carried out to give comparative figures. Peel strengths are typically calculated as force averaged over the peel distance [20]. Such tests have been widely discussed by Moore [21,24].

A more fundamental measurement of adhesive forces can be obtained by measuring the forces interacting between an AFM tip and a fixed point on a surface. Such measurements are known as Local Force Microscopy [25]; this technique has been used in the present study. AFM is ideal for force sensing as it is highly sensitive to displacement, of the order of $0.01 \mathrm{~nm}$ and there is a small tip-sample contact area (typical tip radius is less than $10 \mathrm{~nm}$ ). 
When an AFM tip interacts with a soft sample, such as PDMS, the sample can be deformed by the AFM tip. Upon approach to the surface, the tip is pulled into contact with the surface at the point of mechanical instability, i.e. when the gradient of the interaction force exceeds the cantilever force constant. After this initial contact, the tip is pushed downwards at a constant speed to a pre-set distance. The shape of the approach curve in a force-distance diagram of this process indicates whether the PDMS is deformed by the AFM cantilever and the slope of the curve is a function of the elastic modulus of the PDMS. This slope can be used to derive information about sample hardness and stiffness [25]. When the AFM tip is pulled away from the sample the inverse of the factors causing the approach curve occurs. If both the approach and pull-off curves are straight and parallel, there is no hysteresis; any hysteresis gives information on the plastic deformation of the sample. Adhesive interactions between the polymer sample and AFM tip cause the tip to adhere beyond the contact point on the approach curve. The polymer is deformed by this attraction causing polymer extension under a tensile stress as the tip pulls away from the surface. Once the retraction applied by the AFM overcomes this force of attraction the tip sharply pulls out of the surface to its non-contact position and then returns to its equilibrium position.

AFM adhesion studies use the Johnson-Kendall-Roberts (JKR) approach or other similar contact theories to derive the work of adhesion from the measured pull-off force between an AFM tip of known area and the surface under investigation [26]. Derived from the Hertz model [27] the JKR model describes the adhesive contact between solids. [26,28]. The radius of the circle of contact between two adhesive elastic materials $\left(\mathrm{a}_{\mathrm{JKR}}\right)$ is defined as: 
$a_{J K R}^{3}=\frac{R}{K}\left(P+3 \pi \Delta \gamma R+\left(6 \pi \Delta \gamma R+(3 \pi \Delta \gamma R)^{2}\right)^{1 / 2}\right)$

Equation 3

Where $\Delta \gamma$ is the work of adhesion, $\mathrm{P}=$ the load applied by a spherical indenter of radius $\mathrm{R}$, and $\mathrm{K}$ is the equivalent elastic modulus of the indenter tip.

When a negative force is applied and the two surfaces are pulled apart, separation occurs at the critical force $\left(\mathrm{P}_{\mathrm{c}}\right)$ :

$P_{c(J K R)}=-\frac{3}{2} \pi \Delta \gamma R$

Equation 4

And the contact radius at zero pressure is:

$a_{0(J K R)}^{3}=\frac{6 \pi \Delta \gamma R^{2}}{K}$

Equation 5

Hence, the work of adhesion $(\Delta \gamma)$ can be calculated if the critical separation force $\left(\mathrm{P}_{c}\right)$ is measured and the tip radius is known.

The output of the Local Force Microscopy tests would indicate whether the presence of stearic acid in the PDMS samples influences the modulus of the PDMS and the adhesive interaction between the tip and the surface. A number of studies have been reported which used Local Force Microscopy techniques to investigate the behaviour of polymers in loading and unloading experiments where forces are recorded when an AFM tip pushes into, and pulls out of, a PDMS surface [29-33]

Failure surfaces from peel tests using unmodified PDMS and PDMS containing stearic acid can be examined and analysed to determine the mode of failure and whether additives have migrated to the metal-polymer interface to form a weak boundary layer (WBL). Suitable surface analysis techniques for detection of PDMS and stearic acid at the interfaces include SSIMS, XPS and ATR-FTIR [34-36]. 
In the present study, a combination of surface analytical and Local Force Microscopy is used to provide a scientific explanation for the observed reduction in adhesive joint strength of peel test samples bonded with a PDMS adhesive with low levels of incorporated stearic acid.

\section{Experimental}

\section{Unmodified PDMS}

Sylgard $184^{\mathrm{TM}}$ was prepared from two part kits with a chemical cure accelerator in a 10:1:1 ratio of the vinyl functionalised polysiloxane 'Part $A$ ' to the crosslinker 'Part B' to the Q-3659 cure accelerator. After mixing, the resulting mixture was degassed in a vacuum chamber until formation of bubbles ceased. The degassed liquid was then used to prepare samples, which were left to cure for a minimum of 24 hours at room temperature before testing or analysis.

Stearic acid was ground using a mortar and pestle and passed through a $212 \mu \mathrm{m}$ sieve. The sieved material was stirred into uncured Sylgard $184^{\mathrm{TM}}$ in percentages from 0 to $1 \mathrm{wt} \%$ prior to degassing.

\section{Preparation of Peel Test Specimens}

Degreased aluminium foil pieces (0.06 mm aluminium foil, $99 \%$ purity, annealed), were rinsed in cold deionised water for 2 minutes. Subsequently the substrates were placed in a $5 \mathrm{~L}$ FPL etch solution $\left(\mathrm{H}_{2} \mathrm{SO}_{4} / \mathrm{Na}_{2} \mathrm{CrO}_{4}\right)$ for 5 minutes at $70^{\circ} \mathrm{C}$. On completion of the etch procedure, the substrates were rinsed in deionised water for 2 minutes and dried under ambient conditions until completely dry. 
The FPL etched aluminium foil substrates were bonded with Sylgard $184^{\mathrm{TM}}$ containing stearic acid in the range 0 to $1 \mathrm{wt} \%$. The glue line thickness was controlled using aluminium foil spacers $0.06 \mathrm{~mm}$ thick.

The bonded samples were left to cure for 24 hours under ambient conditions before testing. The test samples measured $30 \mathrm{~mm}$ wide by a minimum of $100 \mathrm{~mm}$ long.

\section{T-Peel Tests}

Mechanical testing was carried out using a Lloyd Instruments 10000 tensometer with a $500 \mathrm{~N}$ load cell and a cross-head separation speed of $50 \mathrm{~mm} / \mathrm{min}$. Samples were tested in a T-peel test configuration with the initial non-bonded section of the peel specimen held in the grips of the tensile test machine. The first $25 \mathrm{~mm}$ of peel were neglected and then the peel strength was measured over the subsequent $75 \mathrm{~mm}$. The average peel strength per unit width was calculated over this length.

\section{Surface Analysis of Failure Surfaces}

\section{Static Secondary Ion Mass Spectrometry (SSIMS)}

A Cameca 3F SIMS instrument was used to analyse the failure surfaces of the peeled samples. A positive ion spectrum was produced using a duoplasmatron ion gun using negative oxygen at $12.5 \mathrm{keV}$. The mass spectrometer was a magnetic sector type. The beam current was $<1 \mathrm{nA}$ and conditions were such that less than $1 \%$ monolayer was removed during analysis. The sample area analysed was $150 \times 150 \mu \mathrm{m}$ with a mass resolution $(\Delta \mathrm{m} / \mathrm{m})$ greater than 250 .

X-ray Photoelectron Spectroscopy (XPS)

XPS spectra were recorded on a VG Scientific Escalab MK 1 with an Al $\mathrm{K}_{\alpha}$ X-ray source $(1486.6 \mathrm{eV})$ operated in constant analyser energy mode. A source potential of $9 \mathrm{kV}$ was used at $20 \mathrm{~mA}$ current. 
Analysis was conducted on $100 \mathrm{~mm}^{2}$ samples from the polymer and metal sides of failed joints from the peel tests.

Attenuated Total Reflectance - Fourier Transform Infrared (ATR-FTIR)

FTIR spectra were collected using a Mattson FTIR Spectrometer with an ATR cell for analysis of surfaces. Spectra were collected from 4000 to $600 \mathrm{~cm}^{-1}$ using 200 scans at $4 \mathrm{~cm}^{-1}$ resolution.

\section{Surface Adhesion Measurements Using Local force Microscopy}

Force-distance curves were obtained using a Veeco Explorer AFM. A dual cantilever contact mode boron doped silicon probe with a conical tip having an angle of $12^{\circ}$ and nominal radius $10 \mathrm{~nm}$ was used. A probe speed of $1 \mu \mathrm{m} / \mathrm{sec}$ was used with the probe being immediately pulled off the surface, i.e. with a dwell time of zero seconds.

Four force-distance measurements were made from three separate areas of the surface of each PDMS sample to ensure reproducibility between repeat tests and between different areas of each sample.

\section{Results/Discussion}

\section{Peel strength}

The peel test data shows that the strength of PDMS bonded aluminium T-peel joints reduces as the stearic acid loading in the PDMS increases; as shown in Figure 3. The error ranges represent one standard deviation of an average of five samples. The results show that there is a graduated reduction in peel strength as stearic acid content is increased. This follows the same trend observed using $90^{\circ}$ and $180^{\circ}$ peel samples of aluminium bonded with stearic acid doped PDMS [19]. 
Overall, between $0 \mathrm{wt} \%$ and $1.0 \mathrm{wt} \%$ stearic acid addition there was a $60 \%$ reduction in peel strength.

\section{Failure surfaces}

Positive ion SSIMS spectra were taken from both the metal and polymer side of the peeled adhesive joints. The spectra of all the samples showed peaks characteristic of PDMS at 28, 43, 73, 147, 207, 221 and 281 amu [37]. Peaks characteristic of stearic acid would be present at 267 and $285 \mathrm{amu}$ [37]. A peak at $267 \mathrm{amu}$ was present in the spectra of both unmodified PDMS and PDMS containing stearic acid, however, the peak at $285 \mathrm{amu}$ was not present in any of the spectra. Spectra of PDMS failure surfaces are shown for unmodified PDMS and PDMS with $0.3 \mathrm{wt} \%$ stearic acid, see Figures $4 \mathrm{a}$ and $5 \mathrm{a}$.

Peaks due to $\mathrm{Al}(27 \mathrm{amu})$ and $\mathrm{Si}(28 \mathrm{amu})$ in spectra of both the modified and unmodified PDMS suggest mixed mode failure in both cases. Figures $4 \mathrm{~b}$ and $5 \mathrm{~b}$ show spectra of the corresponding metal failure surfaces from these adhesive joints.

The ratios of Al:Si peaks measured using this technique are shown in Table 1. They give an indication of changes in the contribution to failure with stearic acid addition. A comparison of this ratio shows no conclusive increase or decrease in the cohesive component of joint failure. However, it should be noted that unlike XPS, SSIMS data is not regarded as fully as there is no simple linear scaling factor between peak intensity and quantity of an element.

As well as looking for the presence of $\mathrm{Si}(28 \mathrm{amu})$ or $\mathrm{Al}(27 \mathrm{amu})$ peaks to suggest locus of failure, the presence of peaks specific to stearic acid are also of interest. Any such peaks would lend strong support to the WBL theory for bond failure. 
The absence of peaks unique to stearic acid at the interface suggests that the reduced adhesion exhibited with stearic acid modified PDMS is not a result of the formation of a barrier layer of stearic acid at the interface of the adhesive/substrate.

Similarly, XPS was used to analyse the polymer and metal sides of the failure surfaces. As Sylgard $184^{\mathrm{TM}}$ is a PDMS based adhesive, silicon, oxygen and carbon would be expected in a ratio of 1:1:2. This ratio was observed on the polymer surfaces from adhesive joints using both modified and unmodified PDMS see Figures $6 \mathrm{a}$ and 7a. The same peaks were seen in spectra of the metal surfaces, see Figures $6 \mathrm{~b}$ and $7 \mathrm{~b}$. As with the SSIMS data this observation suggests cohesive failure within the boundary polymer immediately adjacent to the metal substrates.

Table 4 shows the chemical composition of the surfaces analysed from XPS data. The presence of peaks due to silicon on the specra of the metal surfaces shows that in all the peel tests failure was cohesive.

The Al:Si ratio on the metal surface would indicate the degree of cohesive failure in the mixed mode failure joints. There is no clear trend of increase or decrease of the degree to which the failure is cohesive with respect to percentage stearic acid although all the data implies cohesive failure within the PDMS. The presence of sulphur detected on some of the metal surfaces is from the etch process carried out to pre-treat the surface prior to bonding.

Analysis of the polymer side of the peel surfaces using ATR-FTIR revealed no differences between the unmodified and the stearic acid modified surfaces.

As with SSIMS and XPS analyses, the metal side of failed joints were used to identify the locus of failure. Figure 8 shows ATR spectra of the metal side of an unmodified joint and three of the stearic acid modified joints. It shows that there is no change in 
the chemical composition of the PDMS bonded to the metal surface on modification with stearic acid.

All the spectra show the presence of the asymmetric C-H deformation at $1413 \pm 4 \mathrm{~cm}^{-}$

${ }^{1}$; $\mathrm{CH}_{3}$ symmetric deformation of $\mathrm{SiCH}_{3}$ at $1257 \pm 4 \mathrm{~cm}^{-1}$; Si-O-Si asymmetric stretch as a doublet at 1006 and $1064 \pm 4 \mathrm{~cm}^{-1}$ and a peak at $788 \pm 4 \mathrm{~cm}^{-1}$ which is attributed to the $\mathrm{Si}-\mathrm{C}$ stretch and the asymmetric $\mathrm{C}-\mathrm{H}$ rock [38]. These peaks are characteristic of PDMS and show that the IR sensitive material on the metal surface is PDMS.

The ATR spectra of the metal surfaces of failed stearic acid modified joints do not show peaks characteristic of saturated carboxylic acids, confirming the absence of stearic acid at elevated levels in this region.

Overall, analysis of the failure surfaces using SSIMS, XPS and ATR-FTIR showed mixed mode failure with some PDMS being transferred to the metal surface. There was no evidence of stearic acid on either the PDMS or the metal failure surface. This suggests that stearic acid does not migrate to the metal polymer interface to form a weak boundary layer (WBL).

\section{Surface Adhesion}

Force-distance curves were obtained for PDMS samples with loadings of $0,0.5$ and 1 wt $\%$ stearic acid. The output of the AFM was in units of current i.e. nA. A conversion factor of $0.314 \mathrm{~N} / \mathrm{A}$ was used to convert the current output from the AFM into units of force. This was not a true calibration factor determined for the specific system but an average figure typical of the type of AFM probe used which gives relative data on the effect of stearic acid on the properties of the PDMS samples. 
Figure 9 is a typical force-distance curve obtained from the unmodified PDMS surface. A clear jump is observed in the forward curve when the tip 'snaps-in' to the surface as attractive Van-der-Waals forces overcome repulsive forces between the PDMS and silicon surfaces. This effect is mirrored by a 'pull-off' force when the tip is retracted from surface. All the force-distance curves produced using either modified or unmodified PDMS showed that a greater force was required to separate the probe and PDMS surfaces than was needed to bring the surfaces together. Also, separation occurred at a greater distance from the turning point than the 'snap-in' point, which is regarded as the height of the surface, suggesting that the PDMS adhered to the AFM tip and stretched before detaching from it. The difference between the minima of the two curves i.e. the 'snap-in' and 'pull-off' forces is a measure of the strength of adhesion between the AFM probe and the PDMS surface. This value has been used as the adhesive force in this study to eliminate uncertainties in the location of the 'zeropoint' which varied between the individual force-distance experiments. Table 5 shows the average work of adhesion calculated using Equation 4 for samples containing stearic acid at $0,0.5$ and $1 \mathrm{wt} \%$.

Comparison of the AFM force-distance curves for modified and unmodified PDMS shows that the surface adhesion or 'tack' of the PDMS increases with increased loading of stearic acid. This adds further evidence to the absence of a WBL of stearic acid at the interface as such a layer would cause a decrease in surface adhesion. The data showed that the surface adhesion was increased for both the PDMS with 0.5 and $1 \mathrm{wt} \%$ stearic acid compared to the unmodified material. As there was little difference between the pull-off forces for the two modified PDMS samples at 0.5 and $1 \mathrm{wt} \%$, a trend cannot be established from the data taken from the three concentrations. It is possible that the surface adhesion increases with stearic acid concentration up to a 
point between 0 and $0.5 \mathrm{wt} \%$ beyond which the adhesion remains constant. Currently there is insufficient data available to corroborate this hypothesis.

The surface adhesion forces obtained from the AFM traces were used to calculate the work of adhesion on pulling the silicon probe off the PDMS surface by inserting values of $\mathrm{P}_{c}$ into the JKR equation [27,28]:

$$
P_{c(J K R)}=-\frac{3}{2} \pi \Delta \gamma R
$$

\section{Equation 4}

Using a value of $10 \mathrm{~nm}$ for $\mathrm{R}$ (the nominal radius of curvature of the tip of the AFM probe [39]) the work of adhesion $\Delta \gamma$ was calculated. The average values for the interaction between the silicon AFM probe and Sylgard $184^{\mathrm{TM}}$ with $0,0.5$ and $1 \mathrm{wt} \%$

stearic acid were found to be $8.1,13.8$ and $13.6 \mathrm{~mJ} / \mathrm{m}^{2}$ respectively. These values are of the same order of magnitude, but lower than, values for the work of adhesion published for other similar, but different, PDMS systems [40-42].

The gradient of the AFM curves as the probe pushes into, and out of, the PDMS surface give information on the stiffness and hardness of the PDMS. The fact that these lines are not parallel for any of the samples indicates hysteresis as a result of some form of molecular rearrangement or relaxation taking place in the PDMS. The reverse curve is steeper than the forward curve, suggesting that the material has become stiffer over the course of the experiment. As Sylgard $184^{\mathrm{TM}}$ is relatively flexible it is likely that stiffness has a greater influence on the curve gradient than hardness. This gradient was calculated for each curve from the set of adhesive pull-off tests. Table 4 shows the average gradients of the curves produced using PDMS samples containing stearic acid at levels of $0,0.5$ and $1 \mathrm{wt} \%$. It was found that the material stiffness measured in both the loading and unloading curves increased with increased levels of stearic acid. As with the surface adhesion measurement, there was 
a significant difference between the samples with stearic acid added and the unmodified samples but the difference between the samples with the two different concentrations of stearic acid was not statistically significant.

The results suggest that the stearic acid modified PDMS is stiffer than the unmodified material. This confirms the results of a study which showed an increase in modulus of tensile test specimens and an increase in the crosslink density of PDMS as the stearic acid content is increased [43].

As a result of the findings from the peel tests and AFM pull-off tests, it is proposed that PDMS modified by addition of low levels of stearic acid becomes tackier and forms a stronger bond with the aluminium foil used in peel tests. When the foil is peeled stress concentrations at the metal-polymer interface are higher with PDMS made stiffer by addition of stearic acid, causing the adhesive bond to break cohesively in the PDMS close to the metal surface. As the stress is more concentrated in this region with the stiffer, stearic acid modified PDMS, the force required to peel the joint is lower than for systems with unmodified PDMS.

Therefore, the proposed mechanism for the reduced adhesion is a bulk stiffening effect of the stearic acid modified PDMS coupled with softer PDMS at the polymermetal interface, rather than a decrease in surface adhesion caused by formation of a weak boundary layer of stearic acid. The surface of the stearic acid modified PDMS in fact becomes more adhesive and forms a stronger bond than unmodified PDMS. This bulk stiffening effect is likely to be a result of stearic acid accelerating the PDMS cure reaction such that the final material is more highly cross-linked. Evidence of this catalysis has been shown by kinetic analysis of FTIR and thermal data [43]. 
Future work is planned to investigate how the stiffness and adhesive properties of stearic acid modified PDMS change through a depth profile of a bonded joint to show whether there is any change in stiffness through the depth which could contribute to the reduction in peel strength with stearic acid loading.

\section{Conclusions}

- T-peel tests of aluminium foil bonded with PDMS containing stearic acid in the range $0-1 \mathrm{wt} \%$ showed that stearic acid reduced the peel strength by approximately $60 \%$. The relationship between stearic acid concentration and peel strength approximately fitted an exponential decay curve.

- $\quad$ SSIMS, XPS and ATR-FTIR showed that the failure mode of the specimens was cohesive failure with a thin layer of PDMS remaining on the peeled aluminium surface.

- There was no evidence of stearic acid on either the peeled aluminium or PDMS surface. This observation suggests that stearic acid does not form a weak boundary layer at the interface between PDMS and aluminium.

- Local Force Microscopy measurements using silicon AFM probes on PDMS surfaces containing stearic acid at $0,0.5$ and $1 \mathrm{wt} \%$ showed that pull-off forces, and the related work of adhesion, were increased on addition of stearic acid. These results suggest that the PDMS surface becomes more 'tacky' as a result of the addition of stearic acid. The PDMS system showed a $70 \%$ increase of surface tack in the presence of stearic acid. This result opposed those obtained from peel tests but repeated tests showed that the increase in tackiness was consistent proving that the apparent increase of adhesion on 
addition of stearic acid was not the result of statistical variation. The mechanism by which the surface 'tackiness' increase occurs is uncertain. The AFM data also showed the modulus of the PDMS increased by around $30 \%$ on addition of stearic acid. This increase in modulus is corroborated by data from bulk mechanical tests of stearic acid modified PDMS and FEA analysis of the bonded T-peel joints [43].

- These results suggest a mechanism by which:

1 Stearic acid affects the PDMS cure reaction resulting in a material which is stiffer but has a more adhesive surface than the unmodified PDMS.

2 On peeling, the stiffer modified PDMS is subject to greater stress concentrations at the polymer-metal interface than unmodified PDMS is, causing the PDMS to fail cohesively close to the interface.

3 The increased concentration of stress causes the samples bonded with stearic acid modified PDMS to have lower peel strengths than those bonded with unmodified PDMS.

- This is against the perceived wisdom that stearic acid forms a weak boundary layer between the adhesive and metal substrate. 


\section{References}

1 EU "End of Life Vehicles" Directive (2000/53/EEC)

2 Coulter S, Bras B, Winslow G, Yester S, Designing for Material Separation: Lessons from Automotive Recycling, Proceedings of the 1996 ASME Design Engineering Technical Conferences and Computers in Engineering Conference, (1996) Irvine, California, USA

3 Car Recycling Business in Japan, Japanese Economy Division, Industrial Report (c) JETRO Japan Economic Report, (June-July 2006)

$4 \quad$ Packham D E, J. Adhesion, [54], 133-143 (1995)

5 Pastor-Blas M M, Sanchez-Adsuar M S, Martin-Martinez J M, J. Adhesion, [50], 191-210, (1995)

6 Serre C, Vayer M, Erre R, J. Mat. Sci Lett, [20], 1989-1991 (2001)

$7 \quad$ US Patent 5028649, Efner H F, (1991)

8. US Patent 4519965, Tayler R P, Cekoric M E, Dewhurst J E, Abouzahr S M, (1985)

9. US Patent 4115333, Phipps D L Jr., Wambach A D, (1978)

10. US Patent 54560, Kubots H, (1971)

11 Reeves L A, Kiroski D, Packham D E, Surface and Interface Analysis, [23], 299-306, (1995)

12 Lisensky G C, Campbell D J, Beckman K J, Calderon C E, Doolan P W, Ottosen R M, Ellis A B, J. Chem. Educ., , 76 [4], 537. (1999)

13 BS EN ISO 11339:2005, Adhesives - T-peel test for flexible to flexible bonded assemblies, British Standards Institute, (2005)

14 BS 5350: Part C10: 1991, ISO 8510-1:1990, Methods of test for Adhesives Part C10. $90^{\circ}$ peel test for a flexible-to-rigid assembly, British Standards Institute, (1991)

15 ASTM D 6862-04, Standard Test Method for 90 Degree Peel Resistance of Adhesives, ASTM International, (2004)

16 BS 5350: Part C11: 1991, ISO 8510-1:1990, Methods of test for Adhesives Part C11. $180^{\circ}$ peel test for a flexible-to-rigid assembly, British Standards Institute, (1991)

17 ASTM D 1781-98 (2004), Standard test method for climbing drum peel for adhesives, ASTM International, (2006)

18 ASTM D3167-03a(2004), Standard test method floating roller peel for adhesives, ASTM International, (2004)

19 Ford K M, An Investigation into the Abhesive Effect of Stearic Acid in PDMS, MSc Project Dissertation, (2007)

19 Packham D E, Handbook of Adhesion, $2^{\text {nd }}$ Edition, John Wiley and Sons, Chichester (2005), 311-315

20 Moore D R, Int. J. Adhes. Adhes. [28], 153-157 (2008)

21 Amourox N, Petit J, Léger, Langmuir, [17], 6510-6517, (2001)

22 Pocius A V, Adhesion and Adhesives Technology, Chapter 4, $2^{\text {nd }}$ Edition, Hanser, Germany, (2002)

23 Moore D R, Williams J G, A protocol for determination of the adhesive fracture toughness of flexible laminates by peel testing: Fixed arm and T-peel methods, An ESIS Protocol, (2006)

24 Drelich J, Mittal K, Atomic Force Microscopy in Adhesion Studies, Chapter 2, VSP, Leiden, Boston, (2005) 
25 Johnson K L, Kendall K, Roberts A D, Proc. Roy. Soc. London A, 324, 301313, (1971)

26 Johnson K L, Contact Mechanics, Chapter 4, Cambridge University Press, Cambridge, (1985)

27 Shi X, Zhao Y, J. Adh. Sci. Tech., 18, [1], 55-58, (2004)

28 Choi G Y, Kim S, Ulman A, Langmuir, [13], 6333-6338, (1997)

29 Sun Y, Walker G C, Langmuir, [21], 8694-8702, (2005)

30 Chaudhury M K, Whitesides G M, Langmuir, [7], 1013-1025, (1991)

31 Léger L, Amouroux N, J. Adhesion, [81], 1075-1099, (2005)

32 Mason R, Koberstein J T, J. Adhesion, [81], 765-789, (2005)

33 Brewis D M, Critchlow G W, J. Adhesion, [54] 175-199, (1995)

34 Critchlow G W, Trans IMF, [74], 108-114, (1996)

35 Comyn J, Adhesion Science, Chapter 7, RSC Paperbacks, Cambridge, UK, (1997)

36 Briggs D, Brown A, Vickerman J C, Handbook of Static Secondary Ion Mass Spectrometry (SIMS), John Wiley and Sons, Chichester, UK, (1989)

37 Smith A L, The Analytical Chemistry of Silicones, Wiley InterScience, Chichester, UK, (1991)

38 Veeco Probes: Product information for d Lever Series Probes

39 Wahl K J, Asif S A S, Greenwood J A, Johnson K L, J. Colloid Interface Sci, [296], 178-188, (2006)

40 Ebenstein D M, Wahl K, J. Colloid Interface Sci, [298], 652-662, (2006)

41 Silberzan P, Perutz S, Kramer E J, Chaudhury M K, Langmuir, [10], 24662470, (1994),

42 Ana U, The Attainment of Controlled Adhesion by Incorporation of Low Level Additives in a PDMS-Based Adhesive, Doctoral Thesis, (2005) 


\section{Captions}

Figure 1: Proposed cure reaction of PDMS [12]

Figure 2: Common specimen arrangements for peel tests showing (a) $90^{\circ}$ peel, (b) $180^{\circ}$ peel and (c) T-peel

Figure 3: Variation in Peel Strength with Stearic Acid Content

Figure 4a: SSIMS spectrum of the polymer surface of an unmodified T-peel joint

Figure 4b: SSIMS spectrum of the metal surface of an unmodified T-peel joint

Figure 5a: SSIMS spectrum of the polymer surface of a $0.3 w t \%$ stearic acid modified T-peel joint

Figure 5b: SSIMS spectrum of the metal surface of a $0.3 w t \%$ stearic acid modified Tpeel joint

Figure 6a: XPS spectrum of the polymer side of unmodified T-peel joint

Figure 6b: XPS spectrum of the metal side of unmodified T-peel joint

Figure 7a: XPS spectrum of the polymer side of $0.3 w t \%$ stearic acid modified T-peel joint

Figure 7b: XPS spectrum of the metal side of $0.3 w t \%$ stearic acid modified T-peel joint

Figure 8: ATR-FTIR spectra metal of the surfaces of T-peel joints with PDMS containing 0-0.8\% stearic acid.

Figure 9: Force-distance curve produced between a conical silicon AFM probe and unmodified Sylgard $184^{T M}$ PDMS 
Table 1: Variation in Al:Si peak intensity ratio on metal peel surface with stearic acid content of PDMS from SSIMS data

Table 2: The chemical composition of the polymer and metal side of adhesive joints containing 0-1\% stearic acid from XPS data

Table 3: Variation in adhesion and stiffness of PDMS with increasing levels of stearic acid as measured by $A F M$ 


\section{Figures}

\section{siloxane oligomers siloxane cross-linkers}

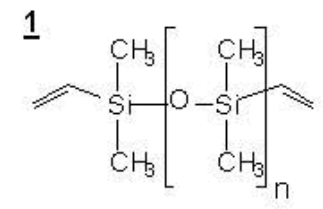

$n=\sim 60$

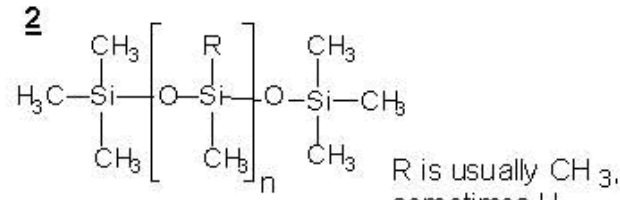

$n=\sim 10$ sometimes $\mathrm{H}$

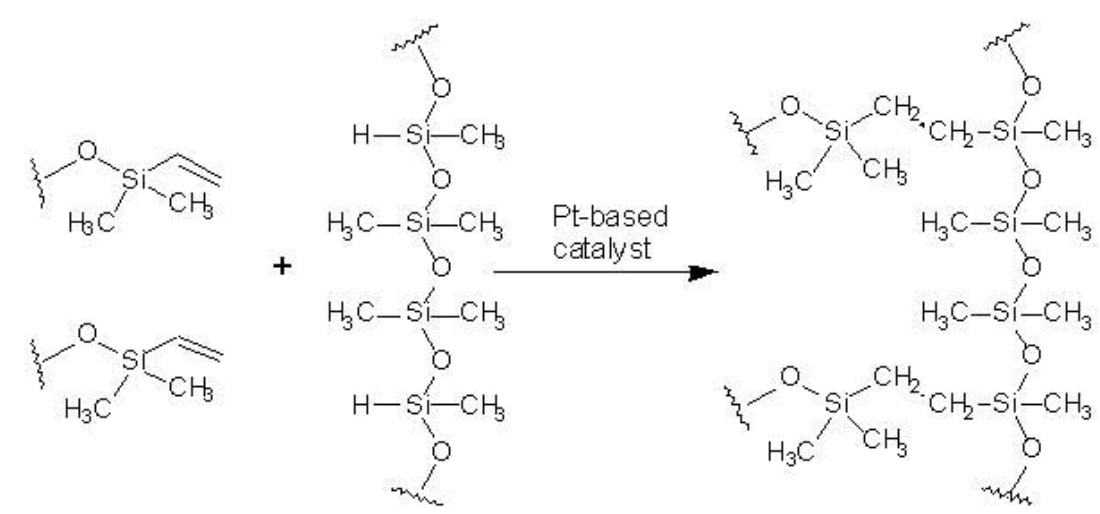

Figure 2: Proposed cure reaction of PDMS [12]

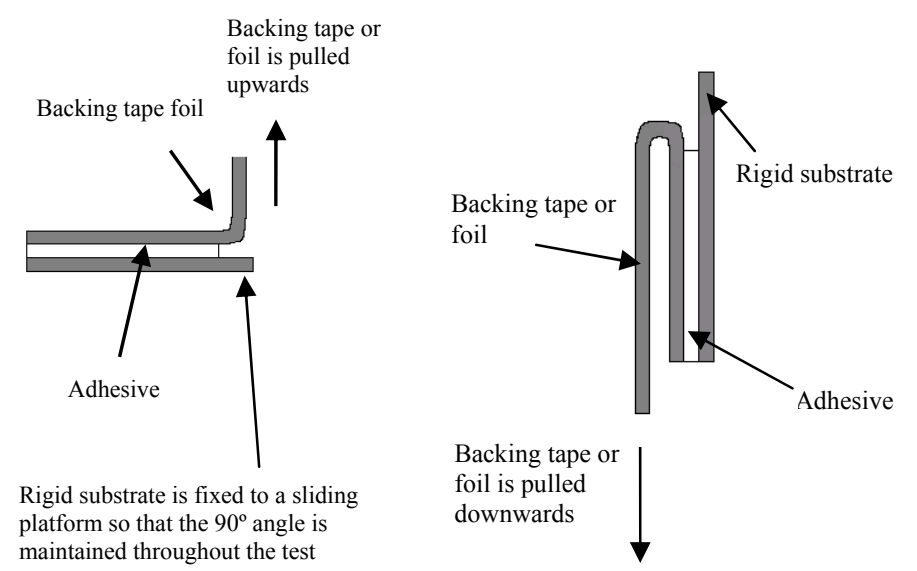

(a)

(b)

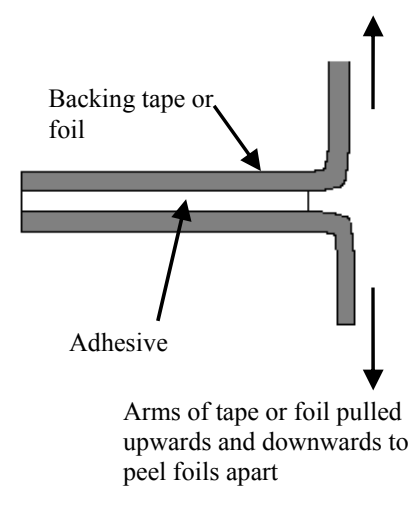

(c)

Figure 2: Common specimen arrangements for peel tests showing (a) $90^{\circ}$ peel, (b) $180^{\circ}$ peel and (c) T-peel 


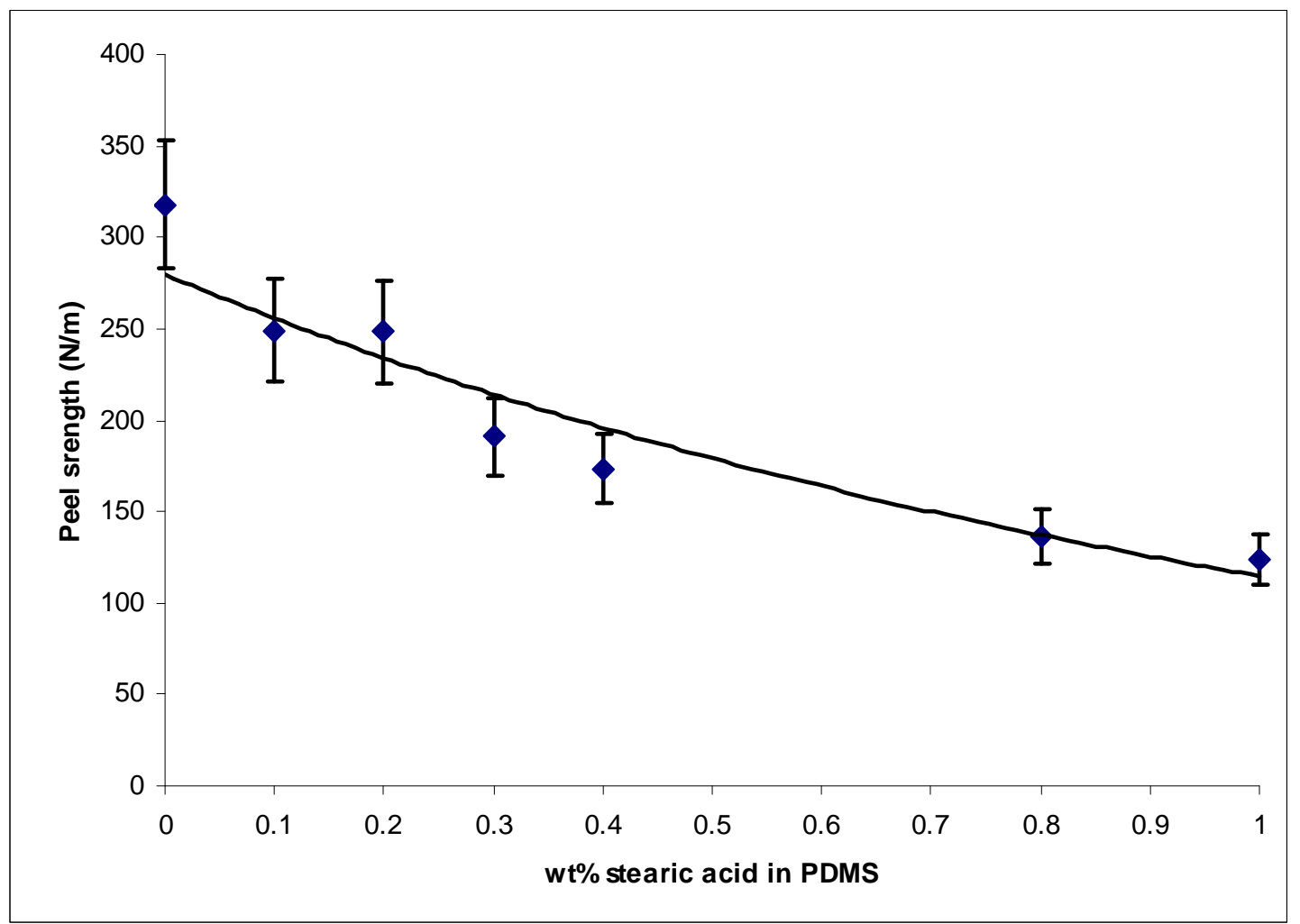

Figure 3: Variation in Peel Strength with Stearic Acid Content

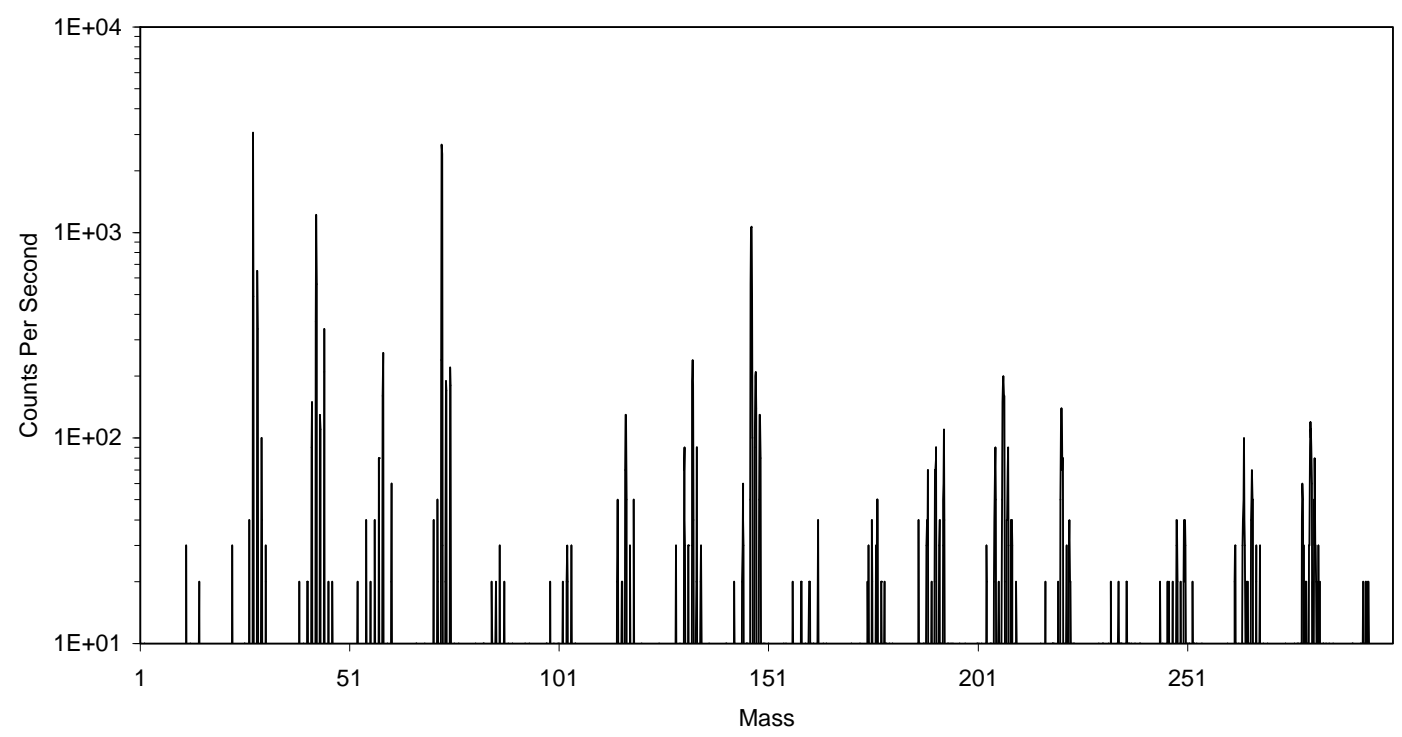

Figure 4a: SSIMS spectrum of the polymer surface of an unmodified T-peel joint 


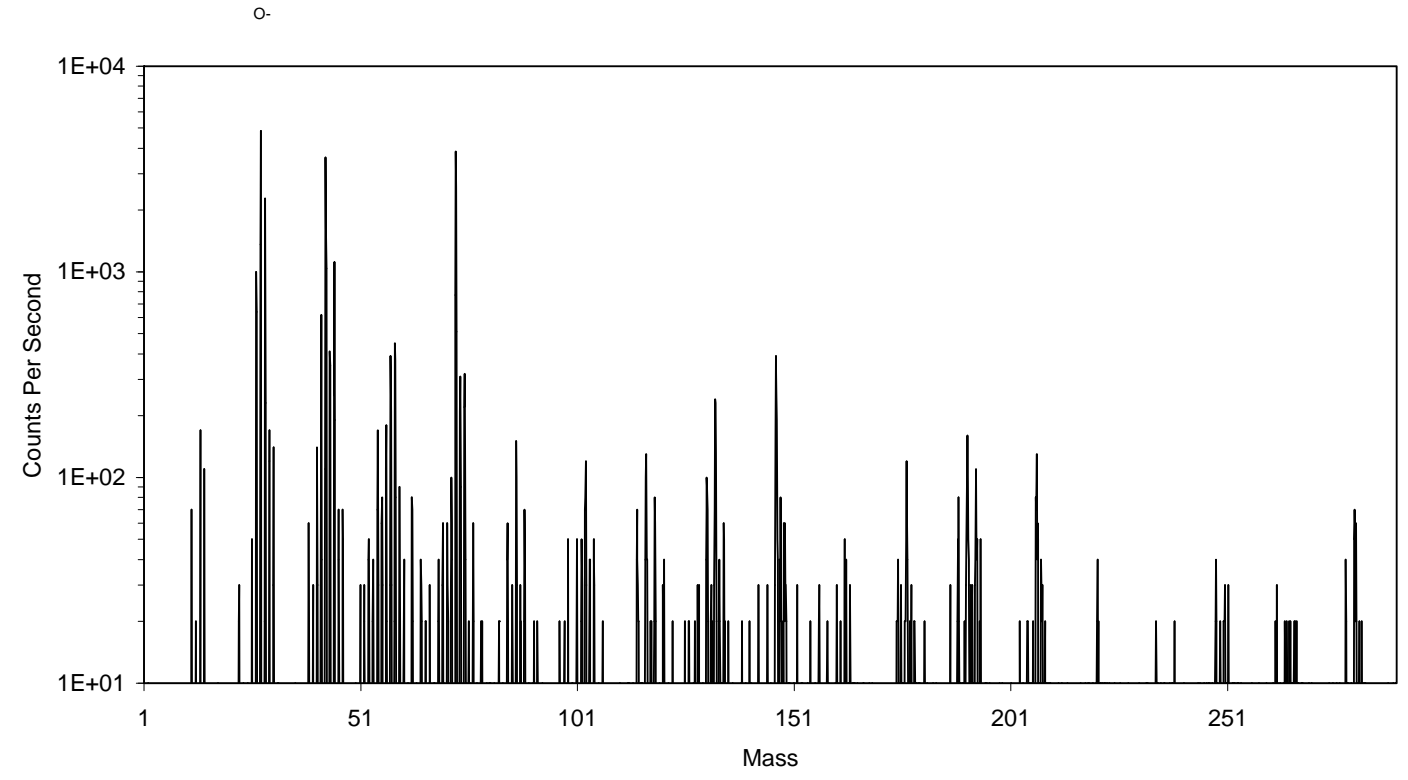

Figure 4b: SSIMS spectrum of the metal surface of an unmodified T-peel joint

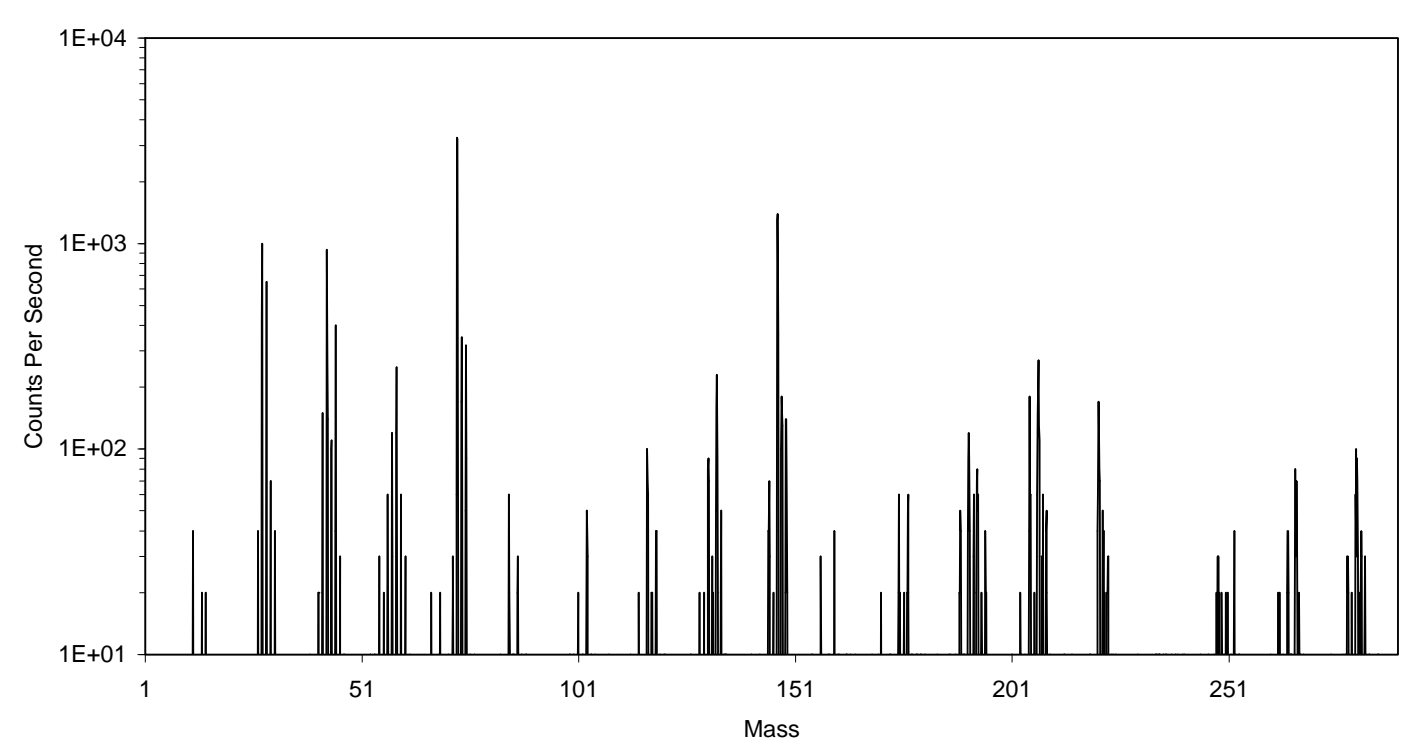

Figure 5a: SSIMS spectrum of the polymer surface of a $0.3 w t \%$ stearic acid modified T-peel joint 


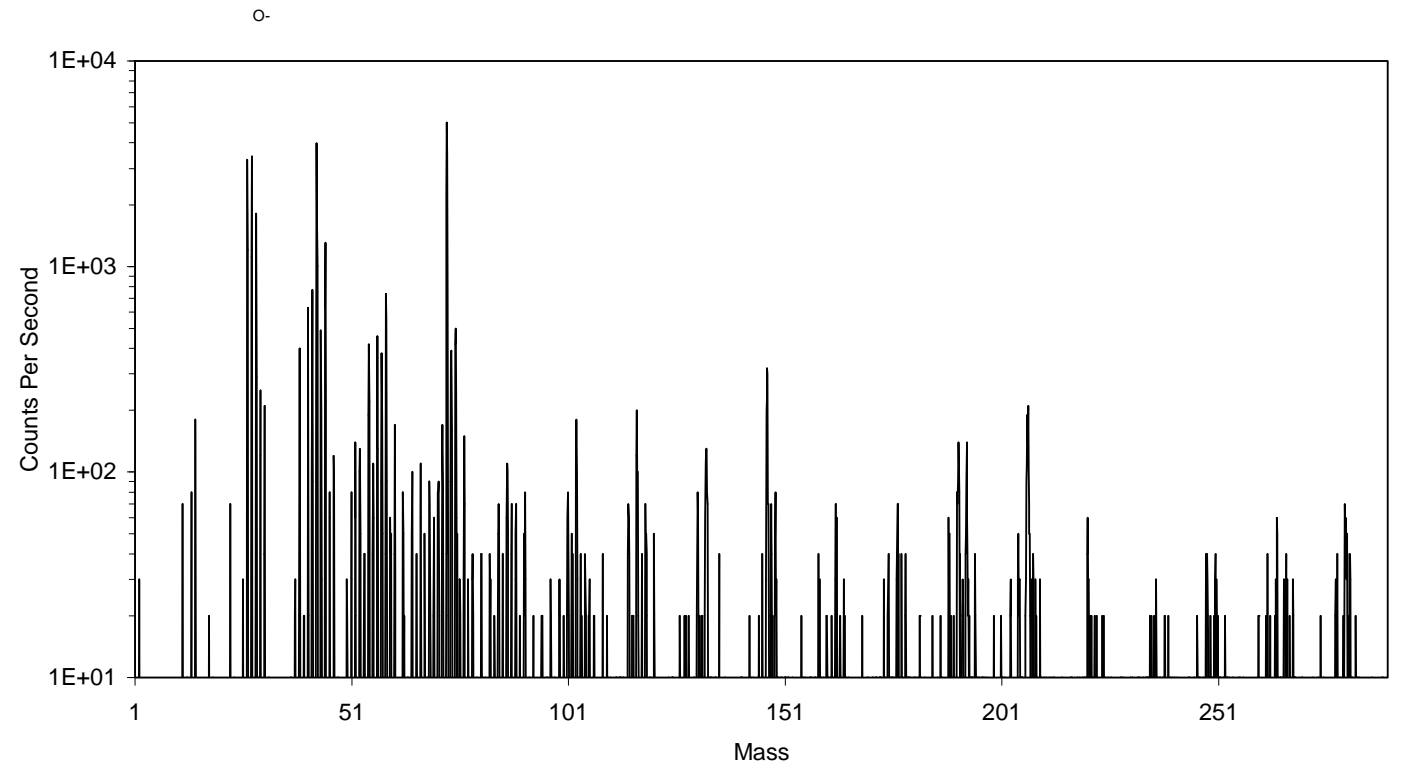

Figure 5b: SSIMS spectrum of the metal surface of a $0.3 w t \%$ stearic acid modified $T$ peel joint

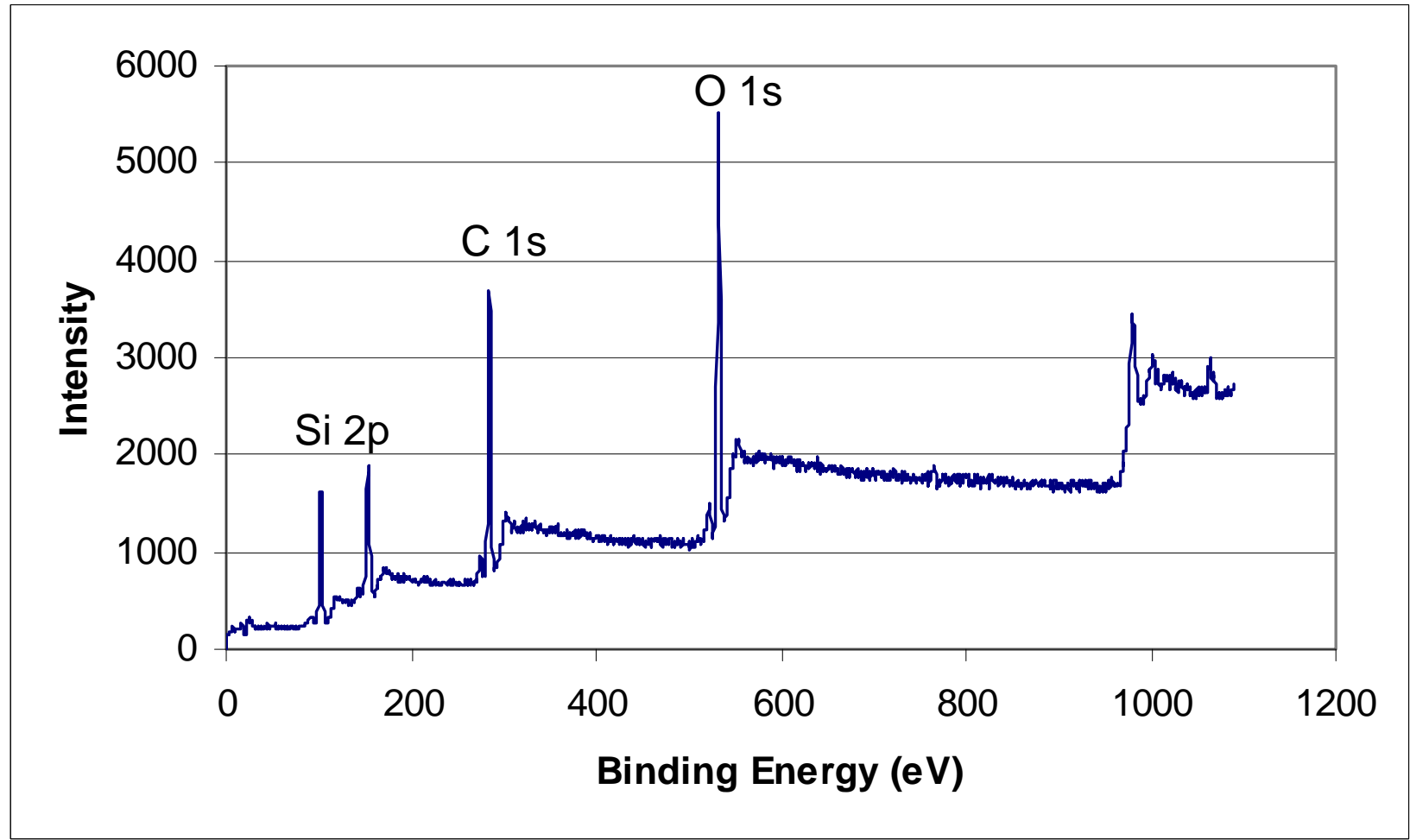

Figure 6a: XPS spectrum of the polymer side of unmodified T-peel joint 


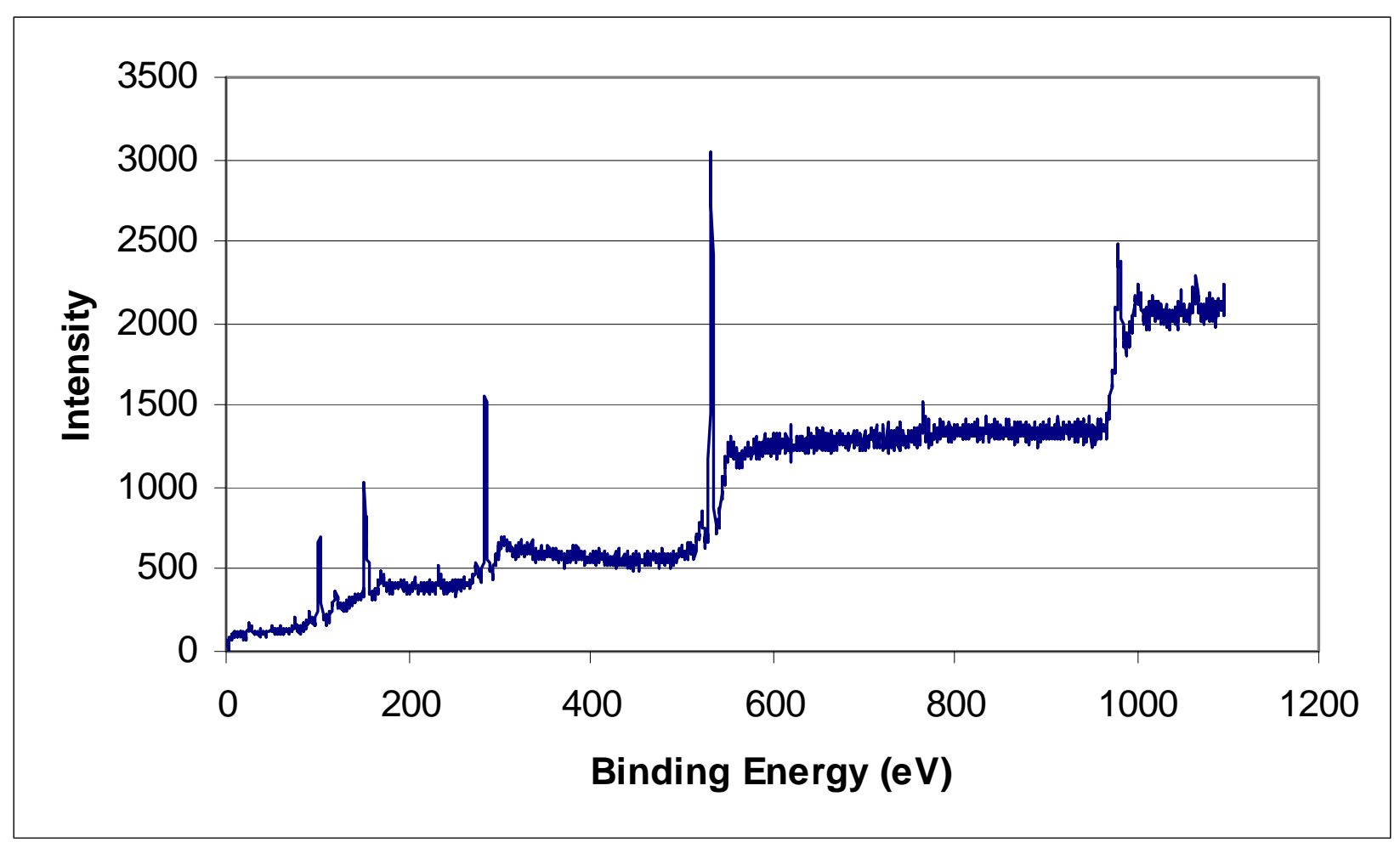

Figure 6b: XPS spectrum of the metal side of unmodified T-peel joint

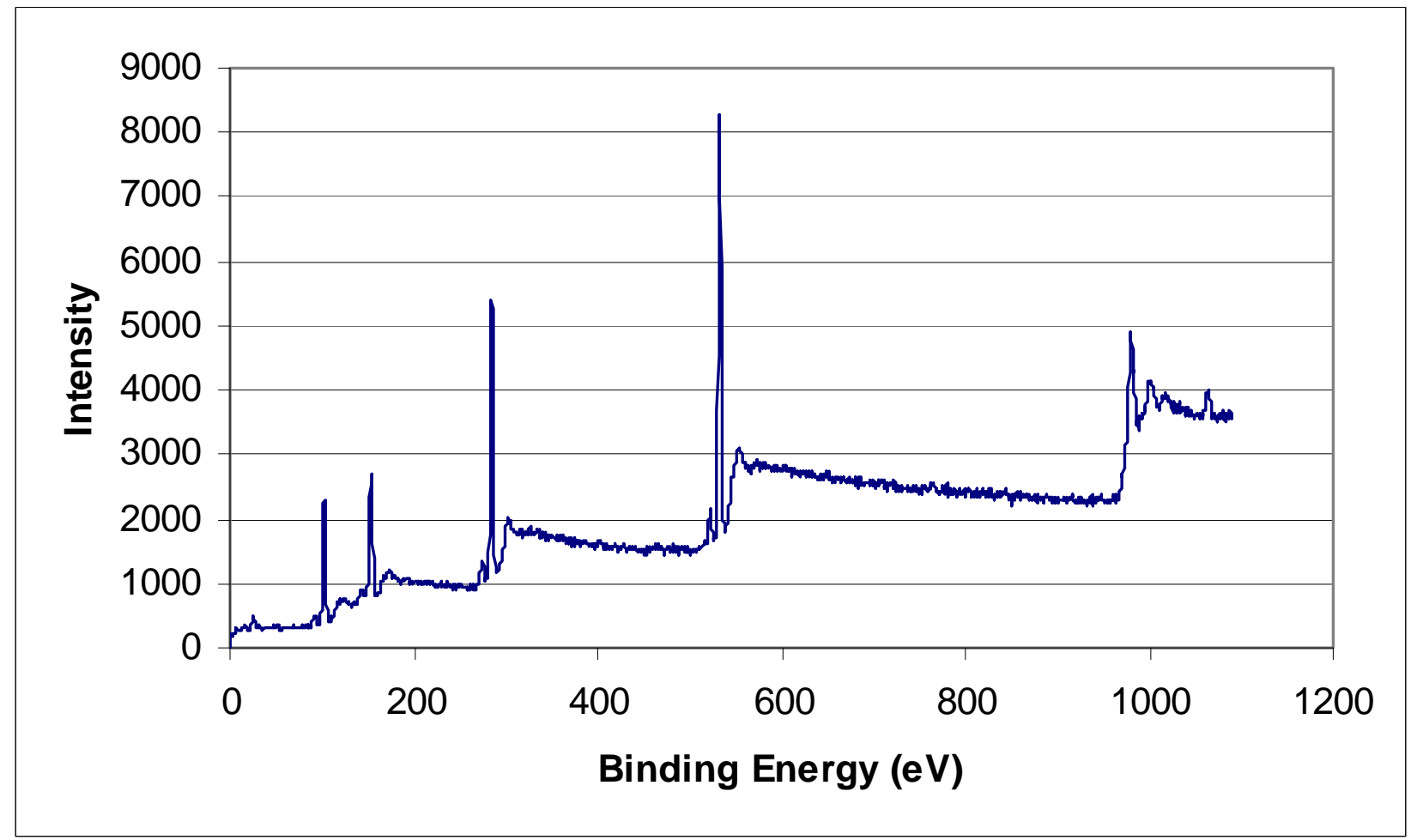

Figure 7a: XPS spectrum of the polymer side of $0.3 \mathrm{wt} \%$ stearic acid modified T-peel joint 


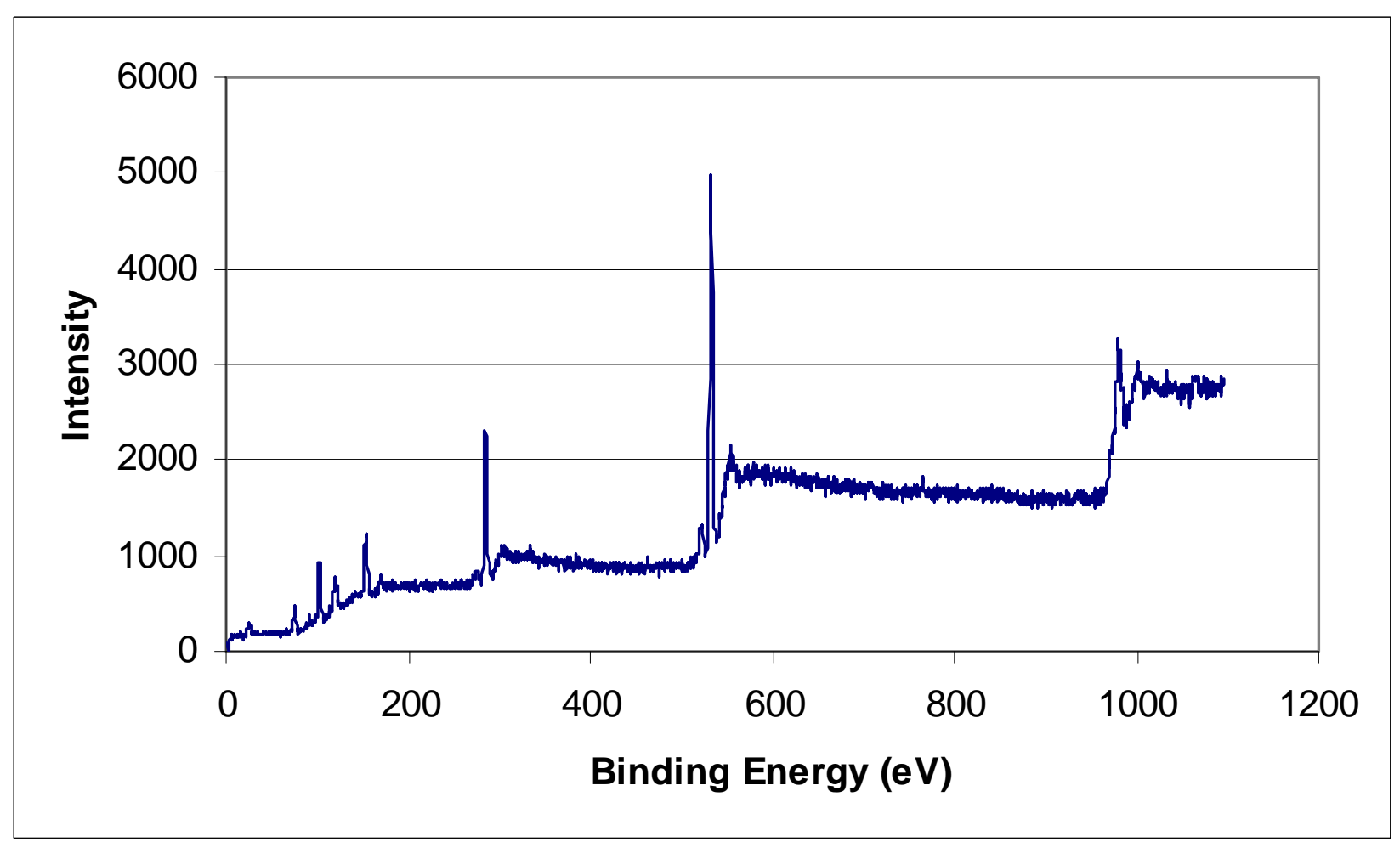

Figure 7b: XPS spectrum of the metal side of $0.3 \mathrm{wt} \%$ stearic acid modified T-peel joint

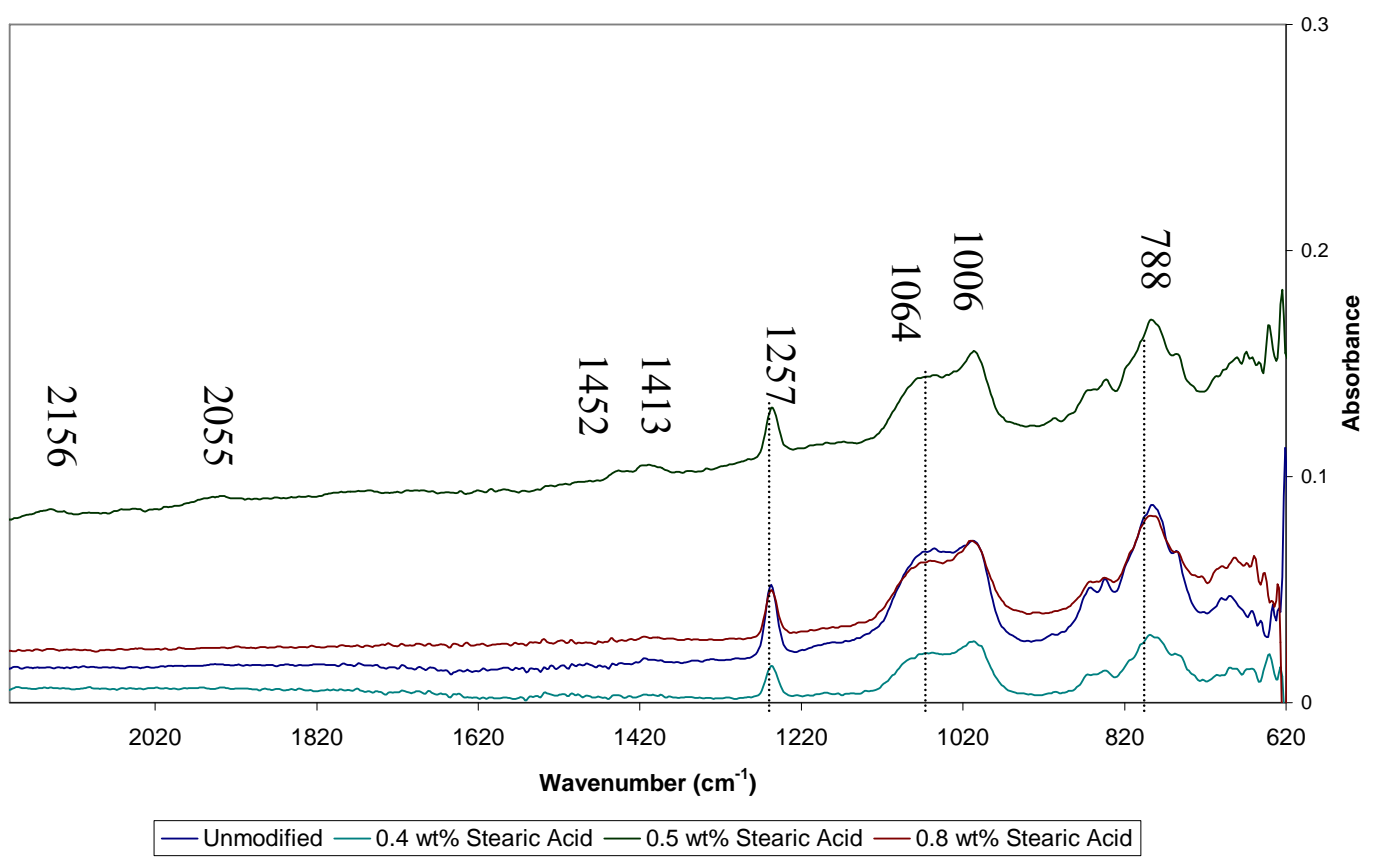

Figure 8: ATR-FTIR spectra of the metal surfaces of T-peel joints with PDMS containing 0-0.8wt\% stearic acid. 


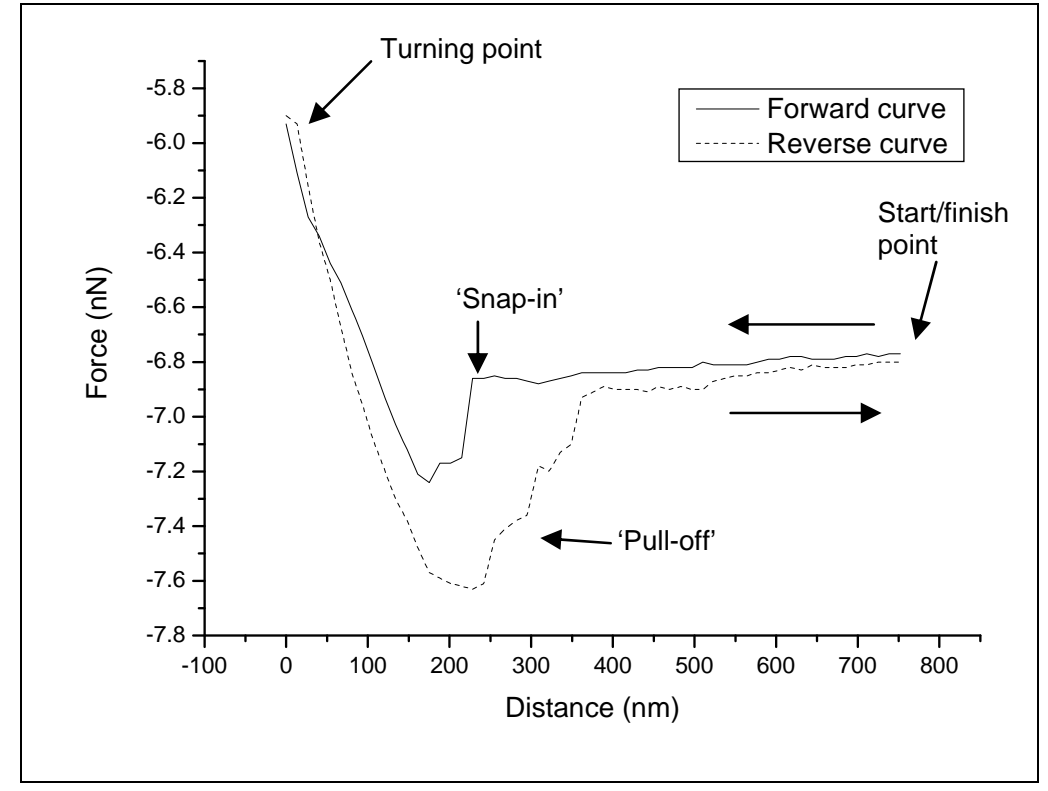

Figure 9: Force-distance curve produced between a conical silicon AFM probe and unmodified Sylgard $184^{T M}$ PDMS 


\section{Tables}

Table 3: Variation in Al:Si peak intensity ratio on metal peel surface with stearic acid content of PDMS from SSIMS data

Stearic acid content $(\mathrm{wt} \%)$

$\mathrm{Al}$ :Si ratio on metal side of failed T-peel joints

\begin{tabular}{cc}
\hline 0 & $1: 5$ \\
0.3 & $1: 1$ \\
0.4 & $1: 50$ \\
1 & $1: 0.5$
\end{tabular}

Table 4: The chemical composition of the polymer and metal side of adhesive joints containing 0-1\% stearic acid from XPS data

\begin{tabular}{|c|c|c|c|c|c|c|c|c|c|c|}
\hline \multirow{3}{*}{$\begin{array}{l}\text { Stearic acid } \\
\text { content }(\mathrm{wt} \%)\end{array}$} & \multicolumn{10}{|c|}{ Element (atomic \%) } \\
\hline & \multicolumn{5}{|c|}{ Polymer side } & \multicolumn{5}{|c|}{ Metal side } \\
\hline & $\mathrm{Si}$ & $\mathrm{O}$ & $\mathrm{C}$ & $\mathrm{Al}$ & $\mathrm{S}$ & $\mathrm{Si}$ & $\mathrm{O}$ & $\mathrm{C}$ & $\mathrm{Al}$ & $\mathrm{S}$ \\
\hline 0 & 26 & 26 & 48 & 0 & 0 & 22 & 32 & 40 & 4 & 2 \\
\hline 0.3 & 25 & 27 & 49 & 0 & 0 & 16 & 35 & 37 & 10 & 2 \\
\hline 0.4 & 25 & 27 & 48 & 0 & 0 & 23 & 29 & 46 & 3 & 0 \\
\hline 1.0 & 25 & 23 & 52 & 0 & 0 & 14 & 32 & 43 & 9 & 2 \\
\hline
\end{tabular}


Table 5: Variation in adhesion and stiffness of PDMS with increasing levels of stearic acid as measured by $A F M$

\begin{tabular}{ccccc}
$\begin{array}{c}\text { \% Stearic } \\
\text { Acid }\end{array}$ & $\begin{array}{c}\text { Adhesion Force }- \\
\text { i.e. difference } \\
\text { between 'snap-in' } \\
\text { and 'pull-off' }(\mathrm{nN})\end{array}$ & $\begin{array}{c}\text { Work of } \\
\text { adhesion } \\
\left(\mathrm{mJ} / \mathrm{m}^{2}\right)\end{array}$ & $\begin{array}{c}\text { Gradient of } \\
\text { forward curve } \\
(\mathrm{N} / \mathrm{m})\end{array}$ & $\begin{array}{c}\text { Gradient of } \\
\text { reverse curve } \\
(\mathrm{N} / \mathrm{m})\end{array}$ \\
\hline 0 & $-0.38 \pm 0.06$ & 8.1 & $-0.0074 \pm 0.0007$ & $-0.0089 \pm 0.0001$ \\
0.5 & $-0.65 \pm 0.12$ & 13.8 & $-0.0120 \pm 0.001$ & $-0.0140 \pm 0.001$ \\
1 & $-0.64 \pm 0.19$ & 13.6 & $-0.0120 \pm 0.001$ & $-0.0138 \pm 0.0009$
\end{tabular}

Error limits at \pm 1 standard deviation 